\title{
Ultrastructural studies of human cutaneous nerve with special reference to lamellated cell inclusions and vacuole-containing cells
}

\author{
MARJORIE J. EVANS, J. B. FINEAN, AND A. L. WOOLF \\ From the Department of Medical Biochemistry and Pharmacology, University of \\ Birmingham, and Midland Centre for Neurosurgery, Smethwick
}

SYNOPSIS One hundred and twenty-nine specimens of human cutaneous nerve obtained from patients suffering from a variety of neuromuscular disorders have been surveyed in detail by electron microscopy. The most striking finding was the presence of lamellated Schwann cell inclusions and of cells containing vacuoles, both of which appear to be derived from myelin and to show some correlation with sensory loss.

Following preliminary electron microscopical studies by Finean and Woolf (1961 and 1962) on human peripheral nerve obtained by biopsy, a systematic survey of whole fascicles in a large number of specimens has been undertaken with a view to revealing information concerning the aetiology of the diseases involved.

\section{MATERIALS AND METHODS}

Invariably, the specimen has been a small branch of the medial antebrachial cutaneous nerve of the forearm taken in the course of muscle biopsy and it has been divided into small segments of which at least two have been fixed immediately on isolation, one in $2 \%$ osmium tetroxide and the other in $0.6 \%$ potassium permanganate, both fixatives at $p \mathrm{H} 7$ in veronal-acetate buffer. The specimens have been embedded in araldite and sections of whole fascicles cut with a diamond knife using a Porter-Blum microtome. The sections were picked up from the water surface with a wire loop and carefully placed on grids covered with a Formvar and carbon film after removal of several grid bars to give large holes. The whole fascicles, which could then be observed without the interference of grid bars, were surveyed with a Siemens electron microscope, type Elmiskop 1.

\section{RESULTS}

Detailed observations have been made on 129 cases. Sensory loss had been recorded (though not necessarily in the forearm) in 41 cases and in $40 \%$ of these degenerative changes were observed. Surveyal of the specimens in groups corresponding to their clinical diagnoses revealed no marked similarities within groups or significant differences Received for publication 23 July 1964. from group to group; for this purpose only groups in which there were four or more specimens were considered and these included carcinomatous, diabetic, nutritional and sensory neuropathies, dermatomyositis, dystrophia myotonica, GuillainBarré syndrome, motor neurone disease, myasthenia, myositis, peripheral neuritis, polyarteritis nodosa, and steatorrhoea.

An analysis of the number of myelinated fibres per fascicle in a sample of the specimens showed that even where there was no reason to expect disease of the sensory neurone there was a wide variation, due mainly to fibre branching, which would mask any small changes for pathological reasons. There were, however, five cases which showed obvious reductions or the absence of myelinated fibres. There were eight cases where there was myelin fragmentation into whorls and droplets similar to that seen in Wallerian degeneration.

In 47 cases, however, lamellated cell inclusions (Fig. 1) were observed whose existence had previously been noted by Finean and Woolf (1962). In seven of the 47 cases and in one other instance vacuolecontaining cells were also apparent (Fig. 2) and in two of these cases, both sensory neuropathies associated with carcinoma, such cells, together with the lamellated inclusions, were numerous and loss of sensation was very marked.

The results of the survey are summarized in Tables I and II.

LAMELLATED CELL INCLUSIONS Lamellated cell inclusions have been observed by Nathaniel and Pease (1963) who noted myelin debris in vacuoles 

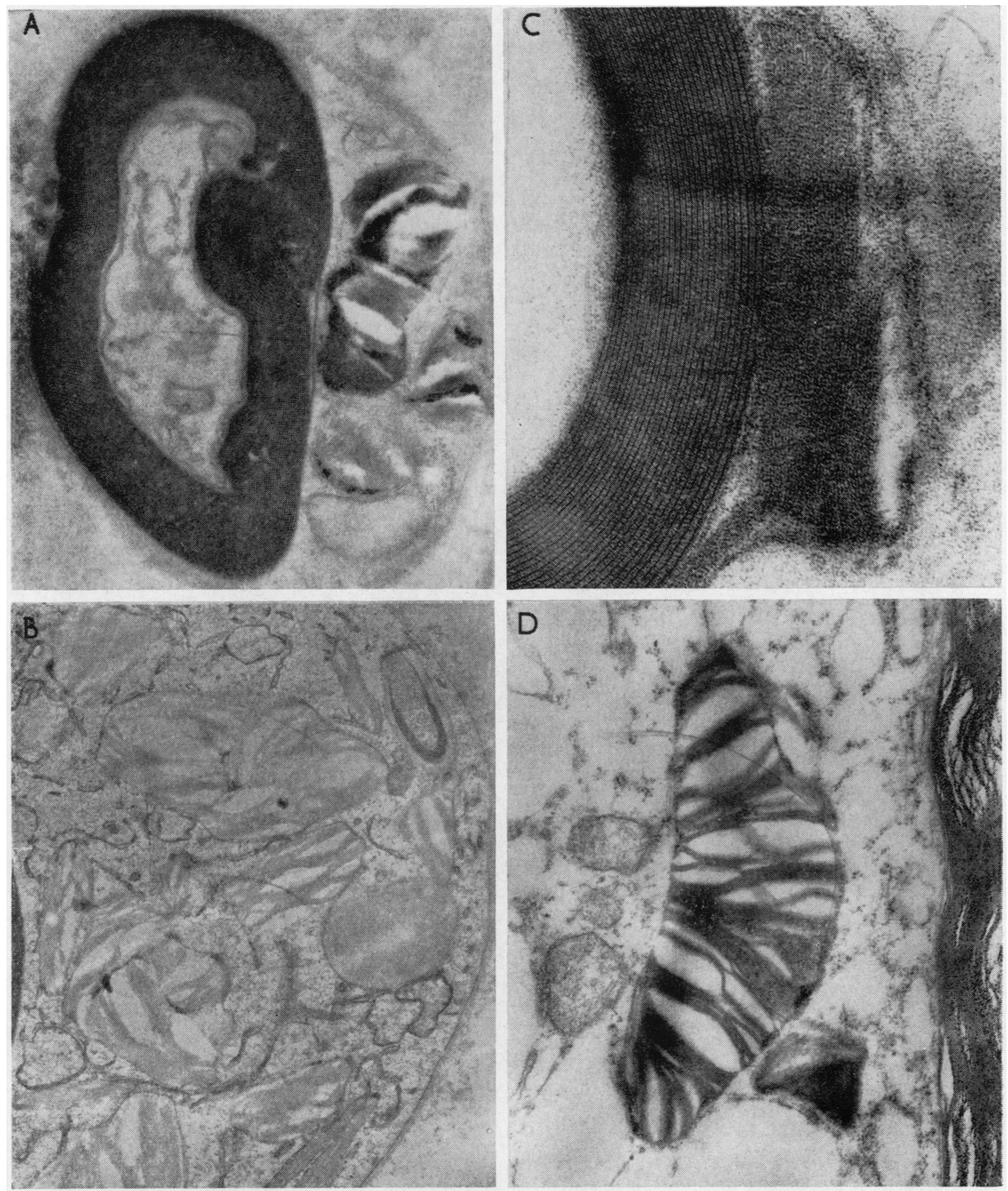

FIG. 1. Examples of cell inclusions observed in a variety of human neurological disorders.

A Permanganate fixation $\times 24,000$.

$B$ Permanganate fixation $\times 15,000$.

C Permanganate fixation $\times 80,000$.

D Osmium fixation $\times 30,000$. 

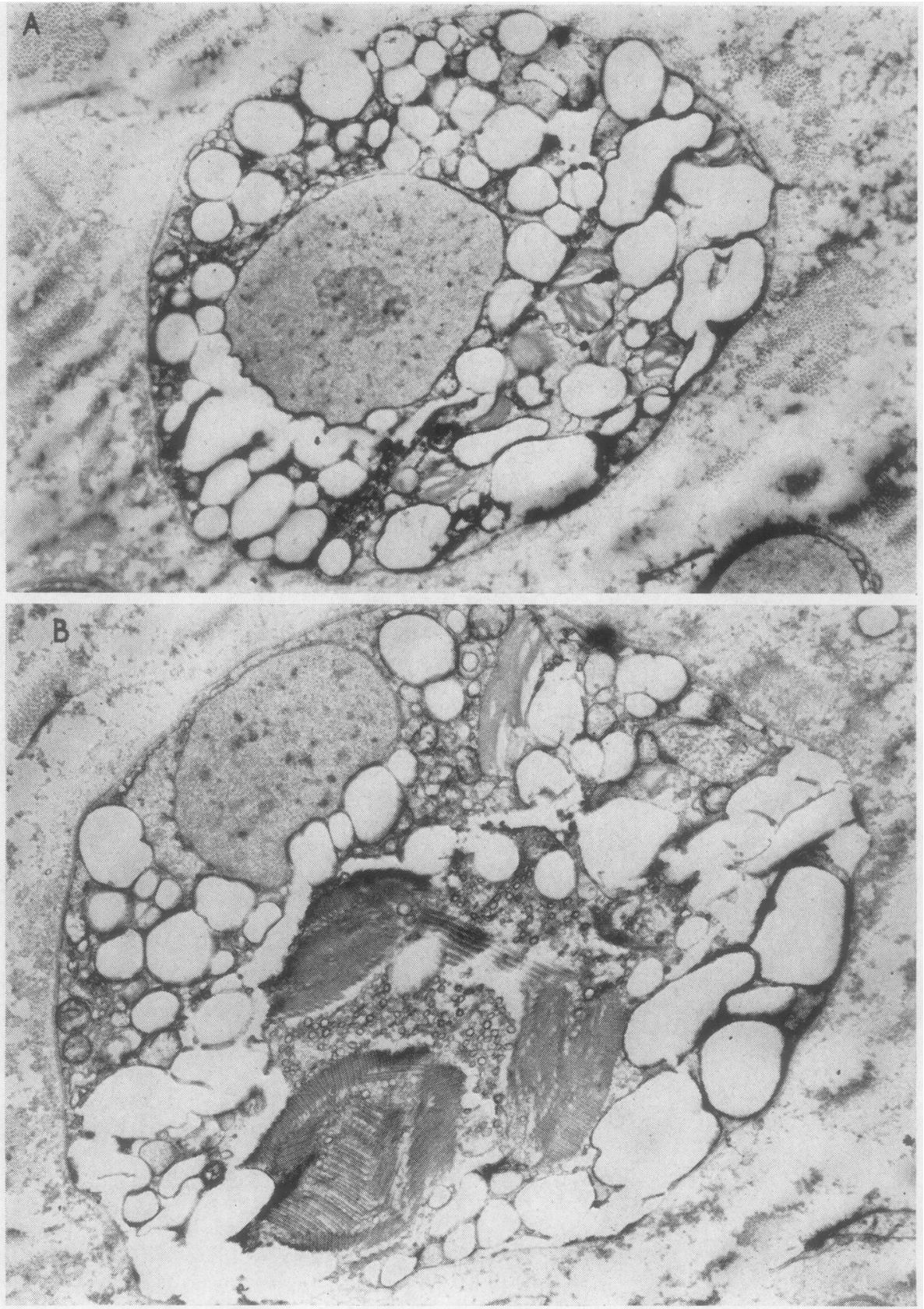

FIG. 2. A A vacuole-containing cell. Permanganate fixation $\times 10,000$.

$B$ Zig-zag layering within a vacuole-containing cell. Permanganate fixation $\times 10,000$. 
TABLE I

CLINICAL FINDINGS CONCERNING SENSORY LOSS

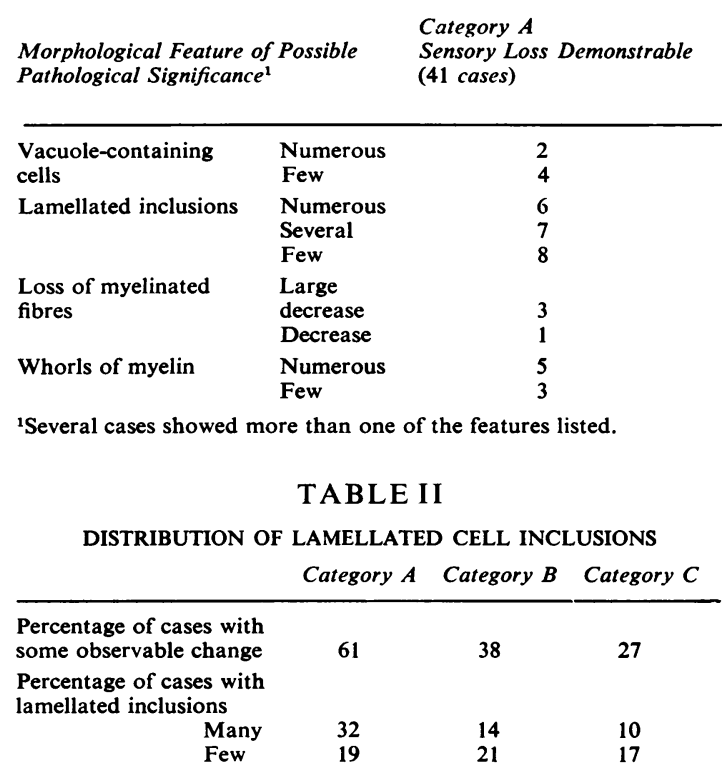

within Schwann cells of rats undergoing Wallerian degeneration, and Webster (1962), who, studying nerve specimens from patients with metachromatic leucodystrophy, found inclusions made up of irregular areas of varying density which tended to be more numerous in the Schwann cells of degenerating myelinated fibres than in any other cells. Although such cell inclusions are by no means identical with those observed in human peripheral nerve, they do seem to be of a similar nature.

The size and shape of the lamellated inclusions varied but they were most frequently of the order of $1 \mu$ in transverse and longitudinal sections. There was a tendency in some cases for them to occur in large numbers (Fig. 1B) and for them to merge into one another. In four cases the inclusions were visible at one level of cutting but not at another, indicating their patchy distribution, and serial sections of individual nerve fibres confirmed that a Schwann cell could contain a number of inclusions at one level and none a few microns away.

The inclusions occurred most frequently in the Schwann cells of myelinated fibres, which often showed proliferations of the endoplasmic reticulum and vacuoles. They also occurred in vacuolecontaining cells and in Schwann cells containing nerve fibres without myelin sheaths, but in these cases there was nearly always evidence of myelin breakdown into droplets and whorls either in the same cell at a different level or in other cells in the

vicinity. It seems, therefore, that the lamellated inclusions may be a product of myelin breakdown. Further evidence that they may be formed from myelin is given in Fig. 1c where an inclusions appears to retain continuity with the myelin sheath.

In the majority of cases layering was very difficult to resolve but where this was possible in permanganate-fixed tissue the periodicity was invariably $50 \AA$, just under half that of normal myelin, and the density of the layering was similar to the density of the intraperiod line in the myelin (Fig. 1C). In cells where the bodies were numerous (Fig. 1B) the layering could not be resolved. The appearance in osmium-tetroxide-fixed preparations was slightly different, as can be seen in Fig. 1D, where the material seems to be in clumps or stands about $250 \AA$ thick, splitting in some places to $125 \AA$, but when the inclusions per cell were numerous no layering could be resolved.

In view of the previous demonstrations cited by Spielmeyer (1922) of small metachromatic granules ( $\pi$-granules) in the cytoplasm of Schwann cells stained with toluidine blue, sections of some araldite-embedded specimens were stained in a similar manner and metachromatic material was observed in a number of cases where the lamellated cell inclusions were numerous.

VACUOLE-CONTAINING CELLS Serial sections through the vacuole-containing cells showed that they extended longitudinally for only 100-200 microns and contained, besides the vacuoles, a nucleus, lamellated cell inclusions similar to those seen within the Schwann cells, and whorls of material of myelinic appearance.

One of these cells was of particular interest in that it contained some very unusual layering. A transverse section through the cell with this zig-zag layering is shown in Figure 2B. The periodicity in the zig-zag portion was of the order of 450 -to $500 \AA$ with the 
darker lines $200 \AA$ wide. This layering was observed only in one cell in one specimen. The layering extended for approximately $20 \mu$, above and below which there were whorls of myelin, vacuoles, and layered bodies.

\section{DISCUSSION}

From Table $I$ it can be seen that a decrease in the number of myelinated fibres and the presence of whorls of myelin are factors related to sensory loss, in agreement with results in the literature (Finean and Woolf, 1961, 1962). The presence of vacuole-containing cells also seems to be a factor related to degeneration of the peripheral sensory neurone and so does the occurrence of large numbers of lamellated bodies. From the last line in Table II it can be seen that the percentage of cases with a few lamellated cell inclusions is similar for all three categories and it seems likely that their presence in very small numbers, i.e., in only one or two Schwann cells per fascicle, may be indicative of minor degenerative changes of a 'wear and tear' nature. Their presence was not, however, related to the age of the patients as in all three categories the range of ages for the appearance of the inclusions was large.

The formation of lamellated inclusions directly from the myelin sheath (Fig. 1c) and their occurrence in conjunction with whorls and droplets of myelin in numerous specimens suggest that they may be breakdown products of myelin. The vacuoles also appear to be related to degeneration of myelin and may represent a chemically more advanced state of degradation where the breakdown products are no longer fixed and consequently are extracted during the preparative procedures for electron microscopy.

Correlation between morphological detection of myelin breakdown and clinical findings is not completely satisfactory, although $40 \%$ of the cases with sensory loss (ignoring those with only a few lamellated bodies and no other morphological changes) showed signs of degeneration. However, even where sensory loss was detectable clinically it did not necessarily extend as far as the site of biopsy, and in samples which have shown degenerative changes these have not always been evident in all sections and could therefore quite easily have been missed. Consequently negative results cannot be regarded as significant, but the presence of large numbers of cell inclusions, especially in specimens which also contained vacuolated cells, suggests that there is some relationship between increasing numbers of cell inclusions and degeneration.

This work was supported by grant no. 324 from the National Multiple Sclerosis Society, New York. The electron microscope was made available by the Wellcome Trust.

\section{REFERENCES}

Finean, J. B., and Woolf, A. L. (1961). J. clin. Path., 14, 152. (1962). J. Neuropath., 21, 105.

Nathaniel, E. J. H., and Pease, D. C. (1963). J. Ultrastruct. Res., 9, 533.

Spielmeyer, W. (1922). Histopathologie des Nervenssystems, vol. 1, p. 114. Springer, Berlin.

Webster, H. deF. (1962). J. Neuropath., 21, 534.

\section{ADDENDUM}

Aurebeck, Osterberg, Blaw, Chou, and Nelson (1964) have recently published electron microscopic observations in metachromatic leucodystrophy and have seen similar cell inclusions in the central nervous system.

\section{REFERENCE}

Aurebeck, G., Osterberg, K., Blaw, M., Chou, S., and Nelson, E., (1964). Arch. Neurol., 11, 273. 